\title{
Extended spectrum beta-lactamase mediated resistance in carriage and clinical gram-negative ESKAPE bacteria: a comparative study between a district and tertiary hospital in South Africa
}

\author{
Raspail Carrel Founou ${ }^{1,2^{*}}$ (D) Luria Leslie Founou ${ }^{1,3}$ and Sabiha Yusuf Essack ${ }^{1}$
}

\begin{abstract}
Background: Gram-negative ESKAPE bacteria are increasingly implicated in several difficult-to-treat infections in developed and developing countries. They are listed by the World Health Organization as resistant bacteria of critical priority in research.

Objectives: To determine the risk factors, prevalence, phenotypic profiles, genetic diversity and clonal relatedness of extended-spectrum $\beta$-lactamase (ESBL)-producing multi-drug resistant (MDR) Gram-negative ESKAPE bacteria in the faecal carriage and clinical samples from patients in an urban, tertiary and a rural, district hospital in uMgungundlovu District, KwaZulu-Natal, South Africa.

Methods: This study took place in a district and tertiary hospital during a two-months period from May to June 2017 in uMgungundlovu district, South Africa. Rectal swabs collected from hospitalized patients, at admission, after $48 \mathrm{~h}$ and at discharge (whenever possible) formed the carriage sample while clinical isolates routinely processed in the microbiological laboratory during the sampling period were also collected and formed the clinical sample. Gram-negative ESKAPE bacteria were screened for ESBL production on selective MacConkey agar and confirmed using ROSCO kits. Minimum inhibitory concentrations were determined, and real-time and multiplex polymerase chain reaction were used to ascertain the presence of bla $a_{\mathrm{CTX}-\mathrm{M}}$ group-1-2-9, bla $a_{\mathrm{CTX}-\mathrm{M}}$ group 8/25, bla $a_{\mathrm{SHV}}$, bla $a_{\mathrm{TEM}}$, bla $a_{\mathrm{OXA}-1 \text {-like, }}$ bla $a_{\mathrm{KPC}}$, bla $a_{\mathrm{VIM}}$, bla $a_{\mathrm{IMP}}$, bla $a_{\mathrm{GES}}$ and AmpC genes. Genomic fingerprinting was also performed using ERIC-PCR. Risk factors for ESBL-mediating MDR Gram-negative ESKAPE colonization were ascertained by univariate and multivariate logistic regression analyses.

(Continued on next page)
\end{abstract}

\footnotetext{
* Correspondence: czangue@yahoo.fr

${ }^{1}$ Antimicrobial Research Unit, School of Health Sciences, College of Health

Sciences, University of KwaZulu-Natal, Durban 4000, South Africa

${ }^{2}$ Department of Clinical Microbiology, Centre of Expertise and Biological

Diagnostic of Cameroon, (CEDBCAM), Yaoundé, Cameroon

Full list of author information is available at the end of the article
}

(c) The Author(s). 2018 Open Access This article is distributed under the terms of the Creative Commons Attribution 4.0 International License (http://creativecommons.org/licenses/by/4.0/), which permits unrestricted use, distribution, and reproduction in any medium, provided you give appropriate credit to the original author(s) and the source, provide a link to the Creative Commons license, and indicate if changes were made. The Creative Commons Public Domain Dedication waiver (http://creativecommons.org/publicdomain/zero/1.0/) applies to the data made available in this article, unless otherwise stated. 
(Continued from previous page)

Results: Overall prevalence of carriage of ESBL-mediating MDR Gram-negative ESKAPE was 37.21\% (16/43), 42.31\% $(11 / 26)$ and $57.14 \%(4 / 7)$ at admission, after $48 \mathrm{~h}$ and at discharge respectively. The prevalence of ESBL-mediating MDR Gram-negative ESKAPE bacteria in faecal carriage (46\%) was higher than clinical samples (28\%). Colonization was mainly associated with the referral from district to tertiary hospital with high statistical significance (OR: 14.40, 95\% Cl 0.98-210.84). bla CTX-M-group-9, bla $_{\mathrm{CTX}-\mathrm{M} \text {-group-1 }}$ and bla $a_{\mathrm{SHV}}$ were the main resistance genes identified. Several patients carried more than two different isolates. A Klebsiella pneumoniae (K1) clone was circulating within wards and between hospitals.

Conclusion: The study highlights the high prevalence of ESBL-mediating MDR Gram-negative ESKAPE bacteria in carriage and clinical samples among hospitalized patients in uMgungundlovu, South Africa. The wide dissemination of these resistant ESKAPE bacteria in hospitals necessitates improvements in routine screening and reinforcement of infection, prevention and control measures.

Keywords: Antibiotic resistance, ESKAPE bacteria, ESBLs, Carriage, Clonality, Hospitalized patients

\section{Introduction}

The selective pressure exerted using antibiotics and aggravated by the dearth of new active substances in the current therapeutic pipeline has led to a considerable increase in antibiotic resistance (ABR) worldwide [1, 2]. A small group of bacteria, i.e., Enterococcus spp., Staphylococcus aureus, Klebsiella pneumoniae, Acinetobacter baumannii, Pseudomonas aeruginosa and Enterobacter spp., termed "ESKAPE" due to their ability to escape the activity of and develop high levels of resistance to multiple antibiotics, have recently gained global attention [3-5]. Of the six infamous ESKAPE pathogens, the four Gram-negative bacteria, i.e., K. pneumoniae, A. baumannii, P. aeruginosa, and Enterobacter spp., have been associated with four major types of multi-drug resistance (MDR), namely extended-spectrum $\beta$-lactamase (ESBL)-producing K. pneumoniae and Enterobacter spp., carbapenemase-producing A. baumannii and metallo- $\beta$-lactamase producing $P$. aeruginosa (MBL-PA) which limit therapeutic options and negatively affect clinical outcomes [3-6]. Several resistance genes have been associated with the emergence of ESBL-mediating MDR Gram-negative ESKAPE bacteria globally. The bacterial production of enzyme hydrolysing antibiotics, particularly $\beta$-lactam antibiotics, is the most common mechanism of resistance in Gram-negative ESKAPE. Beta-lactamase enzymes have emerged following chromosomal mutation and acquisition of resistance genes carried on diverse mobile genetic elements (MGEs) such as plasmids, integrons, insertion sequences, transposons, genomic islands and bacteriophages [7]. The common transferability of resistance amongst bacteria will likely be associated with increasing rates of MDR infections and carriage, although some gaps remain as to the dissemination of multi-drug resistant bacteria in the community and among hospitalized patients.

MDR is increasingly being detected in numerous Gram-negative bacteria because of the extensive antibiotic use in communities and hospitals. Despite considerable efforts for their containment, ESBL-mediating multi-drug resistant Gram-negative ESKAPE bacteria are increasingly implicated in several difficult-to-treat infections in both developed and developing countries $[5,6,8,9]$ and were recently listed by the World Health Organization (WHO) as resistant bacteria of critical priority in research $[3,7,8,10]$. Hospitals remain the main reservoir while immune-compromised patients such as those suffering from diabetes, chronic lung, kidney and cardiovascular diseases and cancers are the most affected. Whilst a better understanding on the impact of faecal carriage of ESBLmediated resistance to Gram-negative ESKAPE bacteria is required, carriage is recognized as a potential risk for transmission and on subsequent development of infections especially in healthcare settings in developing countries due to inadequate infection, prevention and control measures.

In the African continent, antimicrobial resistance issue in general and MDR particularly, has not been adequately illustrated yet due limited financial resources. Knowledge of the burden of multidrug-resistant bacteria in South Africa could thus be valuable both to raise awareness on the necessity to prevent the spread of resistant infections in communities and hospitals, and to ameliorate empirical antibiotic therapy and clinical practice. This study seeks to compare the prevalence of faecal carriage of ESBL-mediated MDR Gram-negative ESKAPE bacteria among patients hospitalized in an urban, tertiary and a rural, district hospital in uMgungundlovu District, South Africa. In addition, the study is an attempt to provide insight into the risk factors associated with this carriage. Finally, the study assesses the phenotypic and genotypic characteristics and clonal relatedness of carriage and clinical ESBL-mediated MDR Gram-negative ESKAPE bacteria.

\section{Materials and methods}

\section{Study population and settings}

This study was conducted in a rural, district and urban, tertiary hospital, encoded for ethical reasons as $\mathrm{H} 1$ and 
H2, respectively, during 2 months from May 2017 to June 2017 in uMgungundlovu district, South Africa. The district hospital (H1) represents the smallest level of hospital and provides four services including obstetrics and gynaecology, paediatrics and child health, general surgery and general medicine with 141 beds. In contrast, the tertiary hospital $(\mathrm{H} 2)$ offers several specialties, receives referral patients according to a nationally agreed referral plan and has approximately 505 beds.

\section{Patient enrolment and questionnaire survey}

Total sampling was performed for the recruitment of participants i.e. all patients older than 18 years old, hospitalized in medical or surgical ward of the hospitals H1 and $\mathrm{H} 2$, and willing to participate were included in the study. Oral and written informed consent was obtained from all study participants after explanation of the procedure and purpose of the study. Patient information was gleaned from questionnaires completed by patients and data from patient records. Information was codified prior to analysis to maintain confidentiality.

\section{Sample collection}

Sample collection took place in both surgical and general medical wards during a two-month period, 1 month at each of the hospitals. Rectal swabs that were collected aseptically with Amies swabs from symptomatic in-patients, at three-time points, at admission, after $48 \mathrm{~h}$ and at discharge (whenever possible) formed the carriage sample. Isolates from symptomatic patients originating from tissue, blood, urine, intravenous catheters, and sputum routinely processed in the microbiological laboratory during the sampling period formed the clinical sample.

\section{Definitions of terms}

The specimen (blood, urine, sputum, tissue, intravenous catheter tips, fluid/aspirate and superficial swab) collected for diagnostic purpose from a symptomatic hospitalized patient was considered clinical sample. The clinical isolates were recovered from clinical samples obtained from patients hospitalized in various units of the selected hospitals. In contrast, carriage sample was the rectal swab collected from hospitalized patients at different time-points (admission, after $48 \mathrm{~h}$ and at discharge) out of diagnostic tests performed at hospitals.

\section{Laboratory analysis}

\section{Identification of gram-negative ESKAPE bacteria}

During the sample collection, all rectal swabs were cultured onto MacConkey agar with and without cefotaxime $(2 \mathrm{mg} / \mathrm{L})$. After incubation for $18-24 \mathrm{~h}$ at $37{ }^{\circ} \mathrm{C}$, each morphotype growing on MacConkey with cefotaxime (MCA + CTX) was subjected to Gram staining, catalase and oxidase tests, followed by biochemical identification with API 20E (bioMérieux, Marcy l'Etoile, France) and Vitek 2 System (bioMérieux, Marcy l'Etoile, France) using the GN card according to the manufacturer's instructions. Pure colonies were stored into Tryptone Soya Broth supplemented with $30 \%$ glycerol at $-20{ }^{\circ} \mathrm{C}$ for future use.

\section{Phenotypic screening}

All growing colonies were phenotypically screened for ESBL, AmpC, KPC, MBL, and OXA-48 production using ROSCO DIAGNOSTICA (Taastrup, Denmark) using 0.5 McFarland on Mueller-Hinton agar according to the manufacturer's instructions.

\section{Antimicrobial susceptibility testing}

Minimum inhibitory concentrations (MICs) were determined via broth microdilution for all presumptive ESBLs and/or AmpCs, and/or MBL producers. Ampicillin, cefoxitin, cefuroxime, cefotaxime, ceftazidime, meropenem, imipenem, ertapenem, amikacin, gentamicin, ciprofloxacin, tigecycline, tetracycline, doxycycline, nitrofurantoin, and colistin constituted the antibiotic panel for carriage isolates. The Vitek ${ }^{\odot} 2$ System and Vitek 2 Gram-negative Susceptibility card (AST-N255) were used to determining the MICs of clinical isolates. The results of MIC tests were interpreted according to the European Committee on Antimicrobial Susceptibility Testing (EUCAST) breakpoints [11] and the MDR which is the resistance to three or more classes of antibiotics was also assessed. Escherichia coli ATCC 25922, K. pneumoniae ATCC 700603 and K. pneumoniae ATCC 51503 were used as controls.

\section{Genomic characterization Genomic extraction}

Genomic DNA of selected strains were extracted using GenElute Bacterial Genomic DNA Kit (Sigma-Aldrich, St. Louis, MO, USA) according to the manufacturer's instructions. Genomic DNA was stored at $-20{ }^{\circ} \mathrm{C}$ for future use.

\section{Multiplex polymerase chain reaction (M-PCR)}

The isolates were subjected to molecular testing using conventional and M-PCR assays to identify $b l a_{\text {СтX-M }}$ group 8/25 (bla $\left.a_{\mathrm{CTX}-\mathrm{M}-\mathrm{gp} 8 / 25}\right)$, bla $a_{\mathrm{SHV}}, b l a_{\mathrm{TEM}}, b l a_{\mathrm{OXA}-1-\text { like, }}$ $b l a_{\mathrm{OXA}-48}, b l a_{\mathrm{KPC}}, b l a_{\mathrm{VIM}}, b l a_{\mathrm{IMP}}$ and $b l a_{\mathrm{GES}}$ genes as previously described [12] (Additional file 1: Table S1).

\section{Real-time polymerase chain reaction (RT-PCR)}

RT-PCR was performed to ascertain $b l a_{\mathrm{AmpC}}$, $b l a_{\text {CTX-M-group-1 }} \quad\left(b l a_{\text {CTX-M-gp } 1}\right), \quad b l a_{\text {CTX-M-group-2 }}$ $\left(b l a_{\mathrm{CTX}-\mathrm{M}-\mathrm{gp} 2}\right)$ and $b l a_{\mathrm{CTX}-\mathrm{M} \text {-group-9 }}\left(b l a_{\mathrm{CTX}-\mathrm{M} \text {-gp } 9}\right)$ resistance genes. Results were analysed on a programmable automate QuantStudio5 ${ }^{\text {tw }}$ (Applied Biosystems, CA, USA) 
using the Taqman Universal Master Mix 2× (Applied Biosystems, CA, USA) and ready-made assays (Thermo Scientific, CA, USA). Thermal temperature running conditions were as follows: UNG activation at $50{ }^{\circ} \mathrm{C}$ for $2 \mathrm{~min}$, initial denaturation at $95{ }^{\circ} \mathrm{C}$ for $10 \mathrm{~min}, 30$ cycles of denaturation at $95{ }^{\circ} \mathrm{C}$ for $10 \mathrm{~s}$, annealing/extension at $60{ }^{\circ} \mathrm{C}$ for $1 \mathrm{~min}$ and a final extension at $60{ }^{\circ} \mathrm{C}$ for $30 \mathrm{~s}$. The results were interpreted with QuantStudio ${ }^{\text {tm }}$ design and analysis software version 1.4 (Applied Biosystems, CA, USA).

\section{Genomic fingerprinting}

Enterobacterial Repetitive Intergenic Consensus-Polymerase Chain Reaction (ERIC-PCR) was used to establish the link of different strains within and between hospitals, wards, carriage and clinical samples as well as across sampling points. The primers ERIC1 5'ATGTAAGCTC CTGGGGATTCAC3' and ERIC2 5'AAGTAAGTGAC TGGGGTGAGCG3' [13] were used and PCR reactions were carried out in a $10 \mu \mathrm{l}$ volume containing $5 \mu \mathrm{l}$ of DreamTaq Green Polymerase Master Mix 2X (Thermo Fisher Scientific, Johannesburg, South Africa), $2.8 \mu \mathrm{l}$ of nuclease free water, $0.1 \mu \mathrm{l}$ of each primer $(100 \mu \mathrm{M})$, and $2 \mu \mathrm{l}$ of DNA template. The reactions were carried out with the following cycling conditions: initial denaturation at $94{ }^{\circ} \mathrm{C}$ for $3 \mathrm{~min}, 30$ cycles consisting of a denaturation step at $94{ }^{\circ} \mathrm{C}$ for $30 \mathrm{~s}$, annealing at $50{ }^{\circ} \mathrm{C}$ for $1 \mathrm{~min}$, extension at $65{ }^{\circ} \mathrm{C}$ for $8 \mathrm{~min}$, a final extension step at $65{ }^{\circ} \mathrm{C}$ for $16 \mathrm{~min}$ and final storage at $4{ }^{\circ} \mathrm{C}$. The generated amplicons were resolved by horizontal electrophoresis on $1.5 \%$ (wt/ vol) Tris-Borate-EDTA (Merck, Germany) agarose gels together with the Quick-load ${ }^{\circ} 1-k b$ (Biolabs, New England) and run in an electric field of $110 \mathrm{~V}$ for $2 \mathrm{~h} 30 \mathrm{~min}$. Electrophoresis gels were visualized by a UV light trans-illuminator, images were captured using a Gel Doc $^{\mathrm{Tm}} \mathrm{XR}+$ system (BioRad Laboratories, CA, Foster City, USA) and analysed by Image Lab ${ }^{\text {tw }}$ Software (version 4.0, BioRad Laboratories, CA, Foster City, USA).

ERIC-PCR profiles were normalized using the Quickload'1-kb (Biolabs, New England) DNA molecular weight marker as the external standard. For cluster analysis, data were exported to Bionumerics software (version 7.6, Applied Maths, TX, USA). Strains were allocated to different clusters by calculating the similarity coefficient from the homology matrix using the Jaccard method. Dendrograms were constructed based on the average linkages of the matrix and using the Unweighted Pair-Group Method (UPGMA). Optimization and band tolerance were set at 1\% (version 7.6, Applied Maths, TX, USA) and 80\% similarity cut-off was used to define clusters.

\section{Data analysis}

Data was coded and entered on an Excel spreadsheet (Microsoft Office 2016) and analysed using STATA (version 14.0, STATA Corporation, TX, USA). Risk factors for ESBL-mediating MDR Gram-negative ESKAPE colonization were ascertained by univariate and multivariate logistic regression analyses. Prevalence of MDR carriage was compared between categories (viz. hospital, ward and time-point) using the chi-square and Fisher's exact test as appropriate. A $p$-value $<0.05$ was regarded as statistically significant.

\section{Results \\ Population characteristics}

A total of 75 hospitalized patients were contacted, amongst whom, $45(60 \%)$ agreed to participate, answered the questionnaire and provided samples. Out of the 45 patients enrolled, faecal carriage was collected from 21 female and 24 were males, and the district hospital $(n=27)$ accounted more participant than the tertiary hospital $(n=18)$. The main reasons of hospitalization were cancer, cellulitis, hypoglycaemia, renal failure, diabetes, breath disorder, surgery and wound, in both hospitals. The patient's follow-up rate was $96 \%, 58 \%$ and $16 \%$ of rectal swabs collected at admission, after $48 \mathrm{~h}$ and at discharge, respectively.

The overall prevalence of carriage was $37.21 \%$ (16/ 43), $42.31 \%(11 / 26)$ and $57.14 \%(4 / 7)$ at admission, after $48 \mathrm{~h}$ and at discharge, respectively, with males being more colonized than females as were patients referred from another hospital (Table 1). Patients in the tertiary hospital were more likely to be colonized by MDR ESKAPE bacteria at admission (50\%) and discharge (66.66\%) than those of the district hospital (Table 1). Furthermore, patients admitted to the general medical ward were more colonized in the district hospital at all time-points whereas, in the tertiary hospital, the prevalence in the surgical ward was higher at admission and discharge. In parallel, the prevalence of MDR ESKAPE bacteria in faecal carriage (46\%) was higher than clinical samples (28\%).

\section{Risk factors for MDR gram-negative ESKAPE bacteria carriage}

Patients referred from the district to the tertiary hospital had an increased the risk of being colonized by resistant bacteria at admission $(\mathrm{OR}=9,95 \% \mathrm{CI} 4.68-17.30)$ and after 48 h $(O R=4 ; 95 \%$ CI 1.50-10.66, Table 2). Similarly, the gender (male) increases the odds of being colonized at admission and after $48 \mathrm{~h}$ in district hospital (Table 2).

The multivariate analysis further confirmed that referral from district to tertiary hospital was significantly associated with MDR Gram-negative ESKAPE bacteria at admission $(\mathrm{OR}=14.40,95 \% \mathrm{CI} 1.0 .98-210.84)$ and after $48 \mathrm{~h}(\mathrm{OR}=5.72,95 \% \mathrm{CI} 0.17-189.00)$ as was the gender for these two time-points in the district hospital (Table 3). 
Table 1 Fecal carriage of resistant Gram-negative ESKAPE bacteria isolated from hospitalized patients in a rural district and a tertiary urban hospital

\begin{tabular}{|c|c|c|c|c|c|c|c|c|c|c|c|c|}
\hline \multirow[t]{2}{*}{ Variables } & \multicolumn{6}{|c|}{ District Rural Hospital $n=27$} & \multicolumn{6}{|c|}{ Tertiary Urban Hospital $n=18$} \\
\hline & $\begin{array}{l}\text { Admission, } \\
(\%)\end{array}$ & $p$ & $\begin{array}{l}\text { After } 48 \text { h, } \\
(\%)\end{array}$ & $p$ & $\begin{array}{l}\text { At discharge, } \\
(\%)\end{array}$ & $P$ & $\begin{array}{l}\text { Admission, } \\
(\%)\end{array}$ & $p$ & $\begin{array}{l}\text { After } 48 \text { h, } \\
(\%)\end{array}$ & $p$ & $\begin{array}{l}\text { At discharge, } \\
(\%)\end{array}$ & $P$ \\
\hline Overall & 29.63 & $\ldots$ & 47.05 & $\ldots .$. & 50 & $\ldots$ & 50 & $\ldots$ & 33.33 & $\ldots$ & 66.66 & $\ldots$ \\
\hline \multicolumn{13}{|c|}{ Socio-demographic factors } \\
\hline \multicolumn{13}{|l|}{ Gender } \\
\hline Female & 21.4 & 0.333 & 33 & 0.229 & 50 & $\ldots$ & 40 & 0.590 & 50 & 0.571 & 50 & 0.386 \\
\hline Male & 38.4 & & 63 & & 0 & & 55 & & 29 & & 100 & \\
\hline \multicolumn{13}{|c|}{ Clinical history } \\
\hline \multicolumn{13}{|c|}{ Previous hospitalization (within one year) } \\
\hline Yes & 13 & 0.206 & 0 & 0.012 & 0 & 0.248 & 20 & 0.106 & 25 & 0.635 & 100 & 0.386 \\
\hline No & 37 & & 67 & & 66.67 & & 64 & & 40 & & 50 & \\
\hline \multicolumn{13}{|c|}{ Antibiotic use (during hospital stay) } \\
\hline Yes & 27.78 & 0.766 & 33.33 & 0.402 & 50 & 1.000 & 33 & 0.522 & 33 & 1.000 & 100 & 0.386 \\
\hline No & 33.33 & & 54.55 & & 50 & & 54 & & 33 & & 50 & \\
\hline \multicolumn{13}{|c|}{ Transferred from another hospital } \\
\hline Yes & 100 & 0.116 & 0 & $\ldots$ & 0 & $\ldots$ & 75 & 0.046 & 50 & 0.343 & 100 & 0.386 \\
\hline No & 27 & & 47 & & 50 & & 25 & & 20 & & 50 & \\
\hline \multicolumn{13}{|l|}{ Hospital ward } \\
\hline Medicine & 40 & 0.187 & 56 & 0.457 & 50 & 1.000 & 40 & 0.590 & 40 & 0.635 & 50 & 0.386 \\
\hline Surgery & 17 & & 38 & & 50 & & 55 & & 25 & & 100 & \\
\hline
\end{tabular}

Out of the 45 patients enrolled, some refused rectal sampling, some were discharged or transferred after $48 \mathrm{~h}$, while other could not be sampled due to their condition, leading to variability in number

\section{Prevalence of MDR gram-negative ESKAPE bacteria}

Out of 159 non-duplicates resistant Gram-negative bacteria isolated, 31 (19.50\%) were MDR Gram-negative ESKAPE bacteria of which $21(67.74 \%)$ were clinical isolates (11 tissue, 2 bloods, 3 urines, 3 intravenous catheters, 2 sputum) obtained after $48 \mathrm{~h}$ from hospitalized patients (15 males and 6 females) with symptomatic infections in different departments (medicine, surgery, intensive care units). Ten (32.26\%) MDR Gram-negative ESKAPE bacteria were isolated from the rectal swab of in-patients
(6 females, 4 males). In the district hospital, seven isolates were identified, five (71.43\%) in carriage and two (28.57\%) in clinical samples. K. pneumoniae $(n=2)$ and E. aerogenes $(n=2)$ were the main bacterial species isolated in carriage samples while $E$. cloacae $(n=2)$ was the sole clinical isolates. In contrast, in the tertiary hospital, five (20.83\%) isolates were identified in carriage and 19 (79.16\%) in clinical samples. The main pathogen identified in carriage was $E$. aerogenes $(n=2)$ while $P$. aeruginosa $(n=7)$ and $A$. baumannii $(n=7)$ were the main clinical isolates.

Table 2 Risk factors associated with faecal carriage of ESBL-producing Gram-negative ESKAPE bacteria (Univariate Logistic regression)

\begin{tabular}{|c|c|c|c|c|}
\hline \multirow[t]{3}{*}{ Variables } & \multicolumn{2}{|l|}{ District hospital } & \multicolumn{2}{|l|}{ Tertiary hospital } \\
\hline & Admission & After $48 \mathrm{~h}$ & Admission & After $48 \mathrm{~h}$ \\
\hline & OR $(95 \% \mathrm{Cl})$ & OR $(95 \% \mathrm{Cl})$ & OR $(95 \% \mathrm{Cl})$ & OR $(95 \% \mathrm{Cl})$ \\
\hline Gender (F or M) & $2.29(0.42-12.50)$ & $3.33(0.45-24.44)$ & $1.8(0.21-15.40)$ & $0.4(0.16-10.02)$ \\
\hline Antibiotic use (Yes or No) & $1.3(0.23-7.32)$ & $0.42(0.05-3.31)$ & $0.43(0.03-5.98)$ & 1 \\
\hline Co-morbidity & $1.05(0.61-1.83)$ & $1.03(0.48-2.24)$ & $1.05(0.61-1.83)$ & $1.03(0.48-2.24)$ \\
\hline Previous hospitalization & $0.24(0.02-2.40)$ & 1 & $0.14(0.01-1.76)$ & $0.5(0.03-8.95)$ \\
\hline Transferred from another hospital & 1 & 1 & $9(0.93-86.52)$ & $4(0.21-75.67)$ \\
\hline Ward (Medicine or Surgery) & $0.3(0.05-1.88)$ & $0.48(0.07-3.35)$ & $1.8(0.21-15.40)$ & $0.5(0.03-8.95)$ \\
\hline
\end{tabular}


Table 3 Predictive risk factors associated with fecal carriage of MDR Gram-negative ESKAPE bacteria in a district and tertiary hospital (Multivariate Logistic regression)

\begin{tabular}{lllllll}
\hline Variables & District Hospital & & & Tertiary Hospital \\
\cline { 2 - 3 } & Admission; OR (95\% Cl) & After 48 h; OR (95\% Cl) & & Admission; OR (95\% Cl) & After 48 h; OR (95\% Cl) \\
\hline Gender (F or M) & $7.12(0.54-93.75)$ & $3.61(0.34-37.83)$ & & $1.21(0.09-15.61)$ & $0.29(0.005-16.27)$ \\
Antibiotic use (Yes or No) & $4.73(0.28-80.57)$ & $0.93(0.08-11.40)$ & & $0.26(0.007-9.01)$ & $0.41(0.009-17.46)$ \\
Transferred from another hospital & 1 & 1 & & & $14.40(0.98-210.84)$ & $5.72(0.17-189.00)$ \\
Hospital Ward (Medicine or Surgery) & $0.08(0.004-1.39)$ & $0.42(0.05-3.81)$ & & $2.09(0.10-42.29)$ & $1.14(0.03-49.14)$ \\
\hline
\end{tabular}

\section{Antimicrobial resistance profiles}

In the tertiary hospital, especially in the medical ward, isolates expressed high resistance to ampicillin (100\%), cefuroxime $(100 \%)$ and cefotaxime $(100 \%)$ in both carriage and clinical samples (Table 4). Similarly, in the surgical ward of the same hospital, clinical samples showed high resistance to ampicillin (100\%), cefuroxime $(100 \%)$, cefotaxime $(88 \%)$, cefoxitin $(88 \%)$, and nitrofurantoin $(55 \%)$ while the unique carriage isolate was resistant to all the panel of antibiotics tested.

In the district hospital, the isolate identified in carriage samples in the surgical ward displayed maximum resistance (100\%) to all antibiotics except colistin while those detected in medical ward exhibited high level of resistance to ampicillin (100\%), cefuroxime (100\%), cefotaxime $(100 \%)$, ceftazidime $(100 \%)$, cefoxitin $(100 \%)$, amikacin (100\%), gentamicin (100\%), nitrofurantoin $(100 \%)$ and tigecycline (100\%) (Table 4).

\section{Genetic diversity of isolated MDR strains}

Overall, the predominant ESBL genes were $b l a_{\mathrm{CTX}-\mathrm{M} \text {-gp } 9}$ (90\%, 28/31), bla $a_{\mathrm{CTX}-\mathrm{M}-\mathrm{gp} 1}(71 \%, 22 / 31)$, bla $a_{\mathrm{SHV}}(42 \%, 13 /$ $31), b_{\text {CTX-M-gp } 8 / 25}(36 \%, 11 / 31)$, bla $a_{\text {OXA-1-Like }}(29 \%, 9 / 31)$ and $\operatorname{bla}_{\mathrm{TEM}}(23 \%, 7 / 31)$ for both carriage and clinical samples. In the tertiary hospital, bla $a_{\mathrm{CTX}-\mathrm{M} \text {-gp } 9}(100 \%)$, $b l a_{\mathrm{CTX}-\mathrm{M}-\mathrm{gp} 1}(87.5 \%), b l a_{\mathrm{KPC}}(75 \%)$ and $b l a_{\mathrm{VIM}}(50 \%)$ were the main resistance genes detected in $A$. baumannii while $K$. pneumoniae strains harboured mainly $b a_{\mathrm{CTX}-\mathrm{M} \text {-gp } 8 / 25}$ (66.6\%), bla $a_{\mathrm{TEM}}(66.6 \%), b l a_{\mathrm{SHV}}(66.6 \%), \quad b l a_{\mathrm{CTX}-\mathrm{M} \text {-gp } 9}$ $(50 \%)$ and $b l a_{\text {CTX-M-gp } 1}(50 \%)$ (Table 5). It is noteworthy to mention that all isolates harboured at least two resistance genes and a maximum of seven genes were detected in one E. aerogenes (G702R2B5) isolate (Fig. 1b). In the district hospital, bla $a_{\mathrm{CTX}-\mathrm{M}-\mathrm{gp} 9}(100 \%), b_{\mathrm{SHV}}(100 \%)$, and $b l a_{\text {TEM }}(100 \%)$ were the predominant genes in K. pneumoniae whereas $b l a_{\text {СТХ-M-gp } 9}(100 \%)$, bla $a_{\text {OXA-1-Like }}(50 \%)$, $b l a_{\mathrm{CTX}-\mathrm{M} \text {-gp } 1}(50 \%)$ and bla $_{\mathrm{CTX}-\mathrm{M} \text {-gp8/25 }}(50 \%)$ were the main genes identified in E. cloacae (Table 5).

\section{Genomic fingerprint}

ERIC-profiles revealed some associations within species and suggest a likely transmission of resistant ESKAPE bacteria across patients, wards and hospitals (Additional file 2: Table S2). For K. pneumoniae, one main cluster showing high genetic similarities was observed (Fig. 1a). K. pneumoniae strains A111R1B2 and A105R2B2 detected among two patients at admission for the former and after $48 \mathrm{~h}$ for the latter, in the medical ward of the district hospital showed $100 \%$ of similarity and shared common ancestors with one carriage and three clinical strains isolated in the tertiary hospital (Fig. 1a and Additional file 2: Table S2). Similarly, one pair of $E$. aerogenes, A105R1B5 and G702R1B5 isolated from two patients in the medical ward of the district and tertiary hospital, both at admission, also exhibited $100 \%$ of similarity and shared a common ancestor with another strain G702R2B5 collected after $48 \mathrm{~h}$ (Fig. 1b). Although, $A$. baumannii (Fig. 1c) and P. aeruginosa (Fig. 1d) were more genetically diverse, some isolates shared a common ancestor within and between the carriage and clinical samples.

\section{Discussion}

The overall prevalence of carriage at admission was $37.21 \%(16 / 43)$ and we found that $42.31 \%(11 / 26)$ and 57.14\% (4/7) were still MDR ESKAPE carriers after $48 \mathrm{~h}$ and at discharge. Notwithstanding the small sample size, our results showed that the carriage of MDR Gram-negative ESKPAPE bacteria increased with the hospital length of stay. Our results are consistent with a Norwegian prospective cohort study carried out from 2009 to 2011 investigating the risk factors for and duration of prolonged faecal carriage of ESBL-producing K. pneumoniae amongst patients with community acquired urinary tract infections which revealed high prevalence of ESBL faecal carriage (ranging from 15 to 61\%) at six different time points [14].

At hospital level, the rate of carriage at admission in the district hospital (30\%) compared with the tertiary hospital (50\%) suggests that patients admitted to the tertiary hospital are likely to be more colonized by MDR Gram-negative ESKAPE bacteria than those of the district healthcare facility (Table 1). Our findings could be explained by the fact that all patients admitted to this level of the hospital are generally transferred from lower level healthcare facilities of the South African health system. This is further confirmed by the increased odds of being colonized in the univariate and multivariate analysis. 


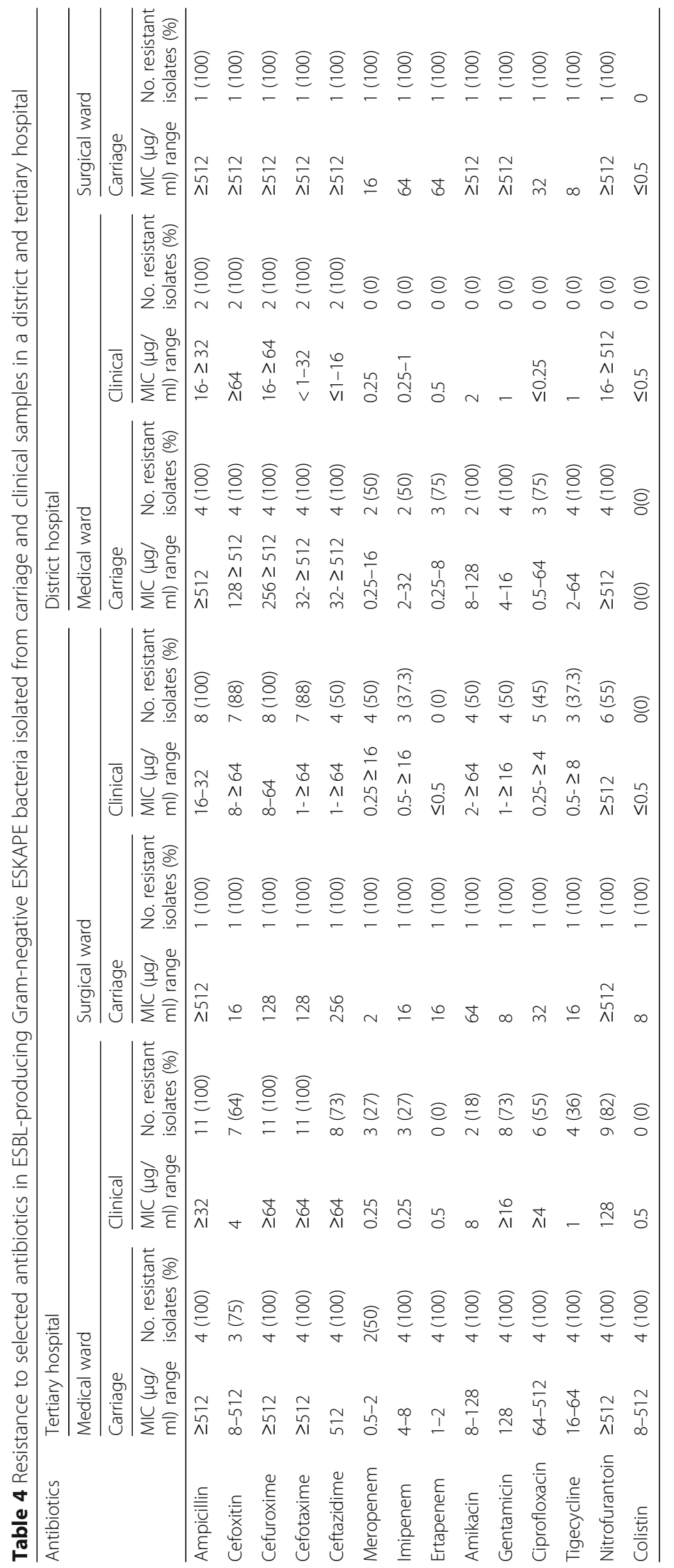


Table 5 Resistance genes in ESBL-producing Gram-negative ESKAPE bacteria

\begin{tabular}{|c|c|c|c|c|c|c|c|c|c|c|c|}
\hline \multirow[t]{2}{*}{ Bacteria } & \multirow{2}{*}{$\begin{array}{l}\text { No. of } \\
\text { strains, } \\
n=31(\%)\end{array}$} & \multicolumn{10}{|c|}{ Resistance genes, $n(\%)$} \\
\hline & & AmpC & TEM & $\mathrm{SHV}$ & CTX-M group-1 & CTX-M group-9 & $\begin{array}{l}\text { CTX-M } \\
\text { Group 8/25 }\end{array}$ & IMP & VIM & KPC & OXA-1-like \\
\hline \multicolumn{12}{|c|}{ Tertiary hospital $(n=24)$} \\
\hline K. pneumoniae & $6(25)$ & $2(33.3)$ & $4(66.6)$ & $4(66.6)$ & $3(50)$ & $3(50)$ & $4(66.6)$ & $1(16.6)$ & $1(16.6)$ & $1(16.6)$ & $2(33.33)$ \\
\hline A. baumannii & $8(33.3)$ & $3(37.5)$ & / & $3(37.5)$ & $7(87.5)$ & $8(100)$ & / & / & $4(50)$ & $6(75)$ & $2(25)$ \\
\hline P. aeruginosa & $7(29.5)$ & $1(14.28)$ & / & / & $7(100)$ & $7(100)$ & / & / & / & / & / \\
\hline E. aerogenes & $2(8.33)$ & $2(100)$ & / & $2(100)$ & / & $2(100)$ & $2(100)$ & / & / & / & $2(100)$ \\
\hline E. cloacae & $1(4.16)$ & / & / & / & $1(100)$ & $1(100)$ & $1(100)$ & $1(100)$ & / & $1(100)$ & / \\
\hline \multicolumn{12}{|c|}{ District hospital $(n=7)$} \\
\hline K. pneumoniae & $2(28.57)$ & / & $2(100)$ & $2(100)$ & $1(50)$ & $2(100)$ & $1(50)$ & / & / & I & $2(33.33)$ \\
\hline P. aeruginosa & $1(14.28)$ & / & / & / & $1(100)$ & $1(100)$ & / & / & / & / & / \\
\hline E. aerogenes & $2(28.57)$ & $1(50)$ & $1(50)$ & $1(50)$ & $1(50)$ & $2(100)$ & $2(100)$ & / & / & I & / \\
\hline E. cloacae & $2(28.57)$ & $1(50)$ & / & $1(50)$ & $1(50)$ & $2(100)$ & $1(50)$ & I & / & / & $1(50)$ \\
\hline
\end{tabular}

Similarly, at discharge, patients of the tertiary hospital (67\%) were more colonized than those of the district hospital (50\%). This could be explained by the complexity of cases associated with invasive medical procedures and greater antibiotic use in the tertiary hospital. However, after $48 \mathrm{~h}$, the prevalence of carriage was higher in patients in the district hospital (47\%) compared with the tertiary hospital (33\%) intimating. This contrast could point out sub-optimal infection prevention and control measures in this level of healthcare setting. Besides, tertiary hospital with its more complicated cases and subsequent higher antibiotic use would have likely created greater selection pressure for resistance, but an anomalously greater resistance was observed in carriage samples in the district hospital. The small sample numbers preclude nonetheless definitive conclusions about carriage rates and resistance patterns.

The prevalence of MDR Gram-negative ESKAPE bacteria in faecal carriage (46\%) was higher than that of clinical samples (28\%) during the study period. Faecal carriage of resistant bacteria has been demonstrated to precede infections and consequently, such high prevalence of asymptomatic faecal carriage is of critical significance. Our results concur with a study from France where the prevalence of MDR Gram-negative bacilli isolated from stool samples was higher than that of clinical samples during a non-outbreak situation in a French Hospital [15]. They are however higher than a report from Mahomed and Coovadia (2014) which demonstrated $4.7 \%$ of faecal carriage of ESBL producing $E n-$ terobacteriaceae amongst children from the community in KwaZulu-Natal, South Africa [16]. Our findings may be an underestimation because of different diagnostic, stewardship practices, preference for empirical treatment and budget constraints such that not every infection generates a microbiological sample.
During the two-months period, 21 clinically relevant MDR Gram-negative ESKAPE bacteria out of 74 isolates were identified in both hospitals. Moreover, the prevalence of MDR $A$. baumannii and $P$. aeruginosa were 41.61\% (10 out of 21 MDR Gram-negative ESKAPE bacteria) and 33.33\% (7 out of 21 MDR Gram-negative ESKAPE bacteria) in clinical samples, respectively. The isolation of three A. baumannii strains, cluster A1, from tissue of three different patients (ED01498924, ED01498793, ED01498924) in surgery, consolidate the likely dissemination of this cluster within this ward in the tertiary hospital (Additional file 2: Table S2 and Fig. 1c).

In carriage samples, MDR K. pneumoniae and Enterobacter spp. were the predominant bacteria in both hospitals. This is consistent with a South African study where $K$. pneumoniae was the main pathogen identified in stool samples of children from the community of KwaZulu-Natal, South Africa [16]. Similarly, a 68\% prevalence of ESBL-producing Enterobacteriaceae faecal carriage was shown amongst Egyptian patients with community-acquired gastrointestinal complaints [17].

An interesting finding was the inter-hospital and interpatient spread of K. pneumoniae (cluster K1) in carriage, which were isolated from two patients (A105R2B2 and A111R1B2) hospitalized in general medicine in district hospital, sharing common ancestor with a patient (G702R3B2) from tertiary hospital (Additional file 2: Table S2). Interestingly, the isolated strains were identified in the medical ward and at different time-points, confirming the dissemination of this cluster across hospitals. In addition, $K$. pneumoniae strains from the same cluster (K1) were detected in urine (ED01500733) and sputum (ED01502268) of clinically ill patients hospitalized in intensive care unit (ICU) and medical ward in the tertiary hospital, respectively. This suggests that 


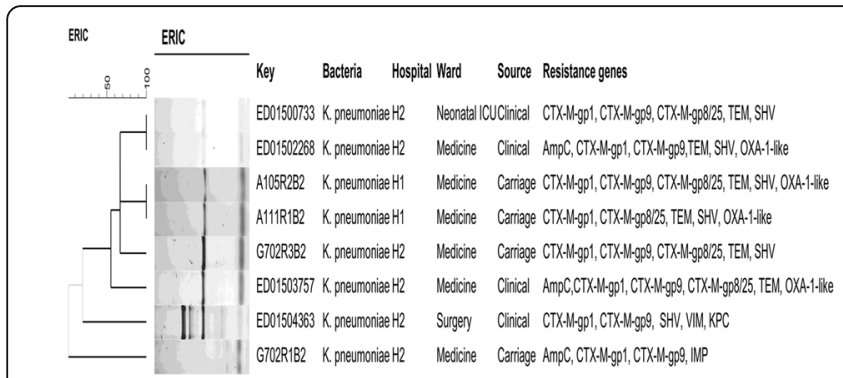

A



C

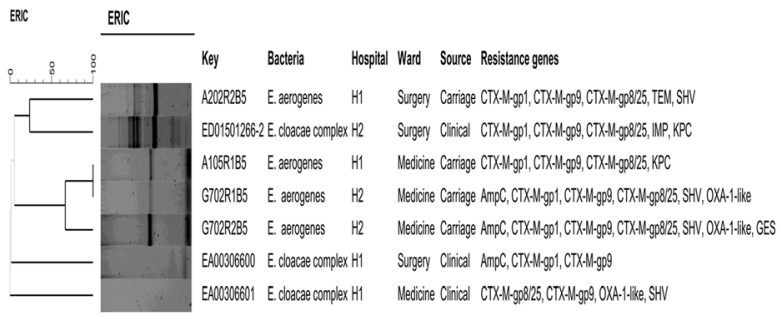

B
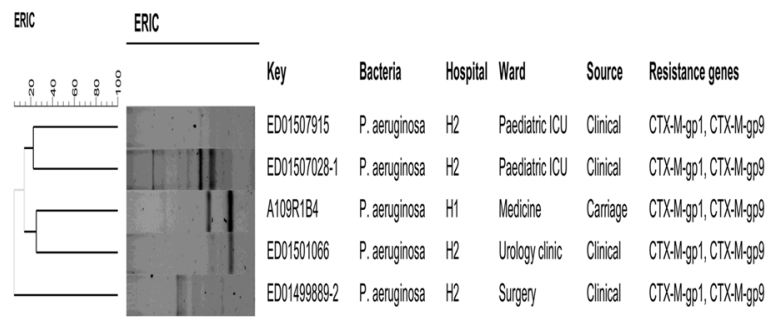

D

Fig. 1 Dendrograms of ESBL-producing of Gram-negative ESKAPE bacteria isolated from carriage and clinical samples from hospitalized patients. a K. pneumoniae, (b) E. aerogenes and cloacae, (c) A. baumannii, (d) P. aeruginosa

the $K$. pneumoniae $\mathrm{K} 1$ strains is circulating within wards and hospitals, and consequently could probably be source of nosocomial infections in hospitals.

Two patients, A105R1B5 and G702R1B5 also carried Enterobacter spp. (cluster E2) at admission in both district and tertiary hospitals, specifically in the medical wards (Additional file 2: Table S2) intimating the emergence of these strains in the community with subsequent entry into the district hospital, as the first level of care, and followed by spread to the tertiary hospital through referral. This result is consistent with our analyses which demonstrated that in the district hospital, the main risk factors were antibiotic use and gender while the referral and hospital ward were the principal risk factors at tertiary level (Tables 2 and 3).

Overall, the predominant ESBLs detected in carriage were $b l a_{\mathrm{CTX}-\mathrm{M} \text {-gp } 9}(90 \%), b l a_{\mathrm{SHV}}(60 \%), b l a_{\mathrm{CTX}-\mathrm{M} \text {-gp } 1}(50 \%)$, $b l a_{\mathrm{TEM}}(40 \%)$ and $b l a_{\mathrm{OXA}-1-\text { like }}(40 \%)$. CTX-M is predominantly reported in community-acquired infections which would be more prevalent in the district hospital as the first level of care. These results are consistent with global reports. For instance, $b l a_{\mathrm{CTX} \text {-M-group }}$ were recently observed in adults in a community in Netherlands and ambulatory patients in Egypt with both gastrointestinal complaints [17, 18]. Similarly, studies from Guinee-Bissau, Niger, Gabon and Tanzania, reported high prevalence of ESBL faecal carriage with $b l a_{\mathrm{CTX}-\mathrm{M}}, b l a_{\mathrm{TEM}}$ and $b l a_{\mathrm{SHV}}$ being the main genes identified [19-21]. The prevalence of AmpC was also higher in carriage (40\%) compared to clinical samples $(23.80 \%)$. Finally, carbapenemases were identified in clinical samples for in these hospitals, specifically, KPC and VIM in clinical A. baumannii isolates as well as IMP in a carriage $K$. pneumoniae isolate. An $E$. aerogenes isolate further showed $b l a_{\mathrm{GES}}$ along with $b l a_{\mathrm{CTX}-\mathrm{M} \text {-gp } 1}, \quad b l a_{\mathrm{CTX}-\mathrm{M}-\mathrm{gp} 9}, \quad b l a_{\mathrm{CTX}-\mathrm{M} \text {-gp } 8 / 25}, \quad b l a_{\mathrm{SHV}}$ and $b l a_{\text {OXA-1-like }}$ in a carriage sample. The faecal carriage of MDR Gram-negative ESKAPE bacteria appears to be a source of cross-transmission between patients. The substantial genetic similarity within and between carriage and clinical isolates as well as wards and hospital settings reveal their potential implications in future outbreak situations that may occur either in hospitals or in communities. Efforts should thus be made amongst communities and asymptomatic patients for better containment of antibiotic resistance dissemination.

Gender, antibiotic use, type of healthcare settings and referral from another hospital were the main risk factors identified. These results suggest that routine screening for MDR Gram-negative ESKAPE bacteria at admission should be implemented, and infection, prevention and control measures reinforced to prevent potential outbreaks by these resistant pathogens [22].

\section{Conclusion}

This study highlights the high prevalence of ESBLmediating MDR Gram-negative ESKAPE bacteria in 
carriage and clinical samples among hospitalized patients in uMgungundlovu. It is imperative to implement regular screening and surveillance of MDR Gram-negative ESKAPE bacteria in communities and hospitals, to monitor epidemiological changes, ascertain socio-economic impact and inform antibiotic treatment. These screening and surveillance measures coupled with strict infection prevention and control programmes and antimicrobial stewardship programmes (ASP) are essential to address antibiotic resistance in these settings.

\section{Additional files}

Additional file 1: Table S1. Oligonucleotide sequences for ESBL and carbapenemase resistance genes included in multiplex PCR assays. (DOCX $17 \mathrm{~kb}$ )

Additional file 2: Table S2. Antibiotic Resistance Profiles and Resistance Genes of Isolates from Single Patients. (DOCX $38 \mathrm{~kb}$ )

\section{Acknowledgments}

The authors would like to express their profound gratitude to Professor Mlisana Koleka, Dr. Sumayya Haffejee and Mrs. Nadira Moodley of the National Health Laboratory of South Africa for their collaboration and for providing us with clinical strains. The Infection, Prevention and Control officers, Mrs. Thandi Masango, Mrs. Jennifer Grace Green and Mrs. Zelda Reddy, are also gratefully acknowledged for their considerable assistance during the sample collection in both hospitals.

\section{Funding}

This work was supported by the Antimicrobial Research Unit (ARU) and a scholarship awarded to R.C. Founou and L.L. Founou by the College of Health Sciences (CHS) of the University of KwaZulu-Natal. The National Research Foundation funded this study through the NRF Incentive Funding for Rated Researchers (Grant No. 85595), the NRF Competitive Grant for Rated Researchers (Grant no:: 106063) and the DST/NRF South African Research Chair in Antibiotic Resistance and One Health (Grant No. 98342) awarded to SY Essack. Any opinions, findings and conclusions, or recommendations expressed in this study are those of the authors, and therefore do not represent the official position of the funders. The funders had no role in the study design, data collection and analysis, preparation of the manuscript nor decision to publish.

\section{Availability of data and materials}

All data generated or analysed during this study are included in this published article and its supplementary information files.

\section{Authors' contributions}

RF co-conceptualized the study, undertook sample collection, laboratory and statistical analyses, prepared tables and figures, interpreted results and drafted the manuscript. LF undertook sample collection and laboratory analyses and vetted the results. SE co-conceptualized the study, undertook vetting of the results and critically reviewed the manuscript. All authors read and approved the manuscript.

\section{Ethics approval and consent to participate}

Ethical approval was obtained from the Biomedical Research Ethics committee (BREC) (No. BF512/16, sub-study of BCA444/16). Permission to conduct the research was also granted from the Department of Health, uMgungundlovu District and hospital managers.

\section{Consent for publication}

Not applicable.

\section{Competing interests}

Professor Essack is a member of the Global Respiratory Infection Partnership sponsored by an unrestricted educational grant from Reckitt and Benckiser. All other authors declare that there is no competing financial interest.

\section{Publisher's Note}

Springer Nature remains neutral with regard to jurisdictional claims in published maps and institutional affiliations.

\section{Author details}

${ }^{1}$ Antimicrobial Research Unit, School of Health Sciences, College of Health Sciences, University of KwaZulu-Natal, Durban 4000, South Africa. ${ }^{2}$ Department of Clinical Microbiology, Centre of Expertise and Biological Diagnostic of Cameroon, (CEDBCAM), Yaoundé, Cameroon. ${ }^{3}$ Department of Food Safety and Environmental Microbiology, Centre of Expertise and Biological Diagnostic of Cameroon, (CEDBCAM), Yaoundé, Cameroon.

Received: 28 May 2018 Accepted: 17 October 2018

Published online: 14 November 2018

\section{References}

1. O'Neill J. Tackling drug-resistant infections globally: final report and recommendations. Rev Antimicrob Resist. 2016.

2. World Health Organization. Antimicrobial resistance global report on surveillance. Geneva: World Health Organization; 2014.

3. Rice LB. Federal funding for the study of antimicrobial resistance in nosocomial pathogens: no eskape. J Infect Dis. 2008;197(8):1079-81.

4. Almasaudi SB. Acinetobacter spp. as nosocomial pathogens: epidemiology and resistance features. Saudi J Biol Sci. 2016; In Press. doi: https://doi.org/ 10.1016/.s.jbs.2016.02.009.

5. Pedleton JN, Gorman SP, Gilmore BF. Clinical relevance of the ESKAPE pathogens. Expert Rev Anti-Infect Ther. 2013;11(3):297-308.

6. Lim C, Takahashi E, Hongsuwan M, Wuthiekanun V, Thamlikitkul V, Hinjoy S, Day NP, Peacock SJ, Limmathurotsakul D. Epidemiology and burden of multidrug-resistant bacterial infection in a developing country. elife. 2016;5. https://doi.org/10.7554/eLife.18082.

7. Dantas G, Sommer MOA. How to fight Back against antibiotic resistance. Am Sci. 2014;102:42-51.

8. Slavcovici A, Maier C. Antimicrobial resistance of ESKAPE-pathogens in culture-positive pneumonia. FARMACIA. 2015;63(2):201-5.

9. Founou RC, Founou LL, Essack SY. Clinical and economic impact of antibiotic resistance in developing countries: a systematic review and metaanalysis. PLoS One. 2017;12(12):e0189621.

10. World Health Organization. Global priority list of antibiotic-resistance Bacteria to guide research, discovery, and development of new antibiotics. Geneva: World Health Organization; 2017.

11. EUCAST. Breakpoint tables for interpretation of MICS and zone diameters. 2017. Available from http://www.eucast.org/clinical_breakpoints/.

12. Dallenne C, Costa AD, Decre D, Favier C, Arlet G. Development of a set of multiplex PCR assays for the detection of genes encoding important b-lactamases in Enterobacteriaceae. J Antimicrob Chemother. 2010;65(3): 490-5. https://doi.org/10.1093/jac/dkp498.

13. Versalovic J, Koeuth T. Distribution of repetitive DNA sequences in eubacteria and application to fingerprinting of bacterial genomes. Nucleic Acids Res. 1991;19(24):6823-31.

14. Jorgensen SB, Soraas A, Sundsfjord A, Liestøl K, Leegaard TM, Jenum PA. Faecal carriage of extended spectrum beta-lactamase producing Escherichia coli and Klebsiella pneumoniae after urinary tract infection - a three-year prospective cohort study. PLoS One. 2017;12(3):e0173510.

15. Vidal-Navarro L, Pfeiffer C, Bouziges N, Sotto A, Lavigne JP. Faecal carriage of multidrug-resistant gram-negative bacilli during a non-outbreak situation in a French university hospital. J Antimicrob Chemother. 2010;65(11):2455-8. https://doi.org/10.1093/jac/dkq333.

16. Mahomed S, Coovadia MY. Faecal carriage of extended Spectrum Betalactamase producing Escherichia coli and Klebsiella pneumoniae in children from the community of Kwadedangendlale, KwaZulu-Natal, South Africa. Int J Infect Control. 2014;11(3):1-8. https://doi.org/10.3396/ijic.v1 1i3.14391.

17. Abdallah HM, Alnaiemi N, Reuland EA, Wintermans BB, Koek A, Abdelwahab AM, Samy A, Abdelsalam KW, Vandenbroucke-Grauls CMJE. Faecal carriage of extended-spectrum $\beta$-lactamase- and carbapenemase-producing Enterobacteriaceae in Egyptian patients with community-onset 
gastrointestinal complaints: a hospital -based cross-sectional study. Antimicrob Resist Infect Control. 2017;6(1):62. https://doi.org/10.1186/ s13756-017-0219-7.

18. Reuland EA, Naiemi N, Kaiser AM, Heck M, Kluytmans JA, Savelkoul PH, Elders PJ, Vandenbroucke-Grauls CM. Prevalence and risk factors for carriage of ESBL-producing Enterobacteriaceae in Amsterdam. J Antimicrob Chemother. 2016;71(4):1076-82. https://doi.org/10.1093/jac/dkv441.

19. Isendahl J, Turlej-Rogacka A, Manjuba C, Rodrigues A, Giske CG, Nauclér P. Fecal carriage of ESBL-producing E. coli and K. pneumoniae in children in Guinea-Bissau: a hospital-based cross-sectional study. PLoS One. 2012;7:e51981.

20. Woerther PL, Angebault C, Jacquier H, Hugede HC, Janssens AC, Sayadi S, El Mniai A, Armand-Lefèvre L, Ruppé E, Barbier F, Raskine L, Page AL, Rekeneire DN, Andremont A. Massive increase, spread, and exchange of extended spectrum beta-lactamase-encoding genes among intestinal Enterobacteriaceae in hospitalized children with severe acute malnutrition in Niger. Clin Infect Dis. 2011;53(7):677-85. https://doi.org/10.1093/cid/cir522.

21. Schaumburg F, Alabi A, Kokou C, Grobusch MP, Köck R, Kaba H, Becker K, Adegnika AA, Kremsner PG, Peters G, Mellmann A. High burden of extended-spectrum beta-lactamase-producing Enterobacteriaceae in Gabon. J Antimicrob Chemother. 2013;68(9):2140-3. https://doi.org/10. 1093/jac/dkt164.

22. Tellevik MG, Blomberg B, Kommedal Ø, Maselle SY, Langeland N, Moyo SJ. High prevalence of Faecal carriage of ESBL-producing Enterobacteriaceae among children in Dar Es Salaam, Tanzania. PLoS One. 2016;11(12): e0168024. https://doi.org/10.1371/journal.pone.0168024.

Ready to submit your research? Choose BMC and benefit from:

- fast, convenient online submission

- thorough peer review by experienced researchers in your field

- rapid publication on acceptance

- support for research data, including large and complex data types

- gold Open Access which fosters wider collaboration and increased citations

- maximum visibility for your research: over $100 \mathrm{M}$ website views per year

At $\mathrm{BMC}$, research is always in progress.

Learn more biomedcentral.com/submissions 